
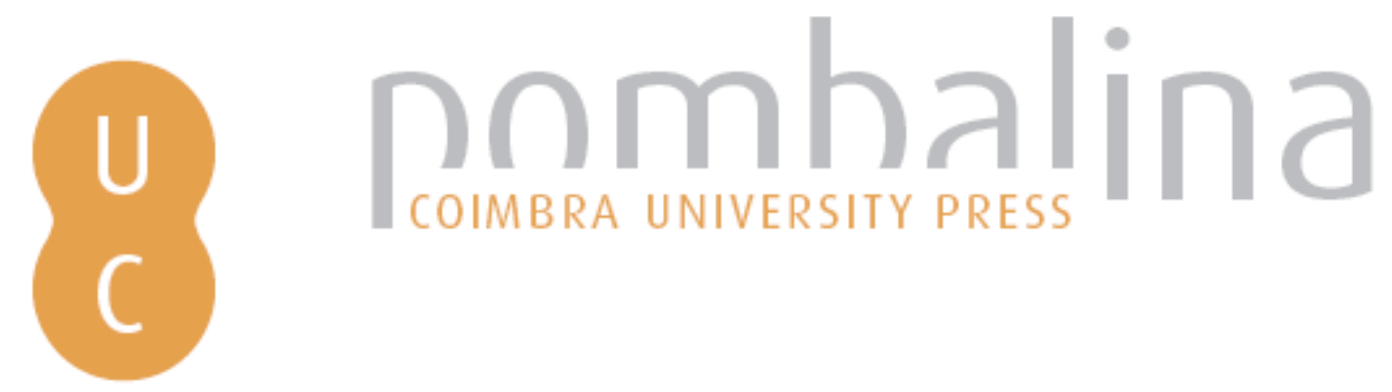

\title{
Análise de susceptibilidades e o ordenamento do território à escala municipal: aplicação aos concelhos de Arruda dos Vinhos e Vila Franca de Xira
}
Autor(es):
Bruno, Inês; Vicêncio, Henrique
Publicado por: Imprensa da Universidade de Coimbra; RISCOS - Associação Portuguesa de Riscos, Prevenção e Segurança
URL persistente:
URI:http://hdl.handle.net/10316.2/34967
DOI:
DOI:http://dx.doi.org/10.14195/978-989-96253-3-4_148
Accessed : $\quad$ 26-Apr-2023 13:34:30

A navegação consulta e descarregamento dos títulos inseridos nas Bibliotecas Digitais UC Digitalis, UC Pombalina e UC Impactum, pressupõem a aceitação plena e sem reservas dos Termos e Condições de Uso destas Bibliotecas Digitais, disponíveis em https://digitalis.uc.pt/pt-pt/termos.

Conforme exposto nos referidos Termos e Condições de Uso, o descarregamento de títulos de acesso restrito requer uma licença válida de autorização devendo o utilizador aceder ao(s) documento(s) a partir de um endereço de IP da instituição detentora da supramencionada licença.

Ao utilizador é apenas permitido o descarregamento para uso pessoal, pelo que o emprego do(s) título(s) descarregado(s) para outro fim, designadamente comercial, carece de autorização do respetivo autor ou editor da obra.

Na medida em que todas as obras da UC Digitalis se encontram protegidas pelo Código do Direito de Autor e Direitos Conexos e demais legislação aplicável, toda a cópia, parcial ou total, deste documento, nos casos em que é legalmente admitida, deverá conter ou fazer-se acompanhar por este aviso.

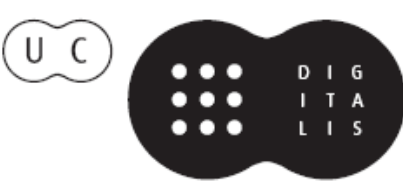



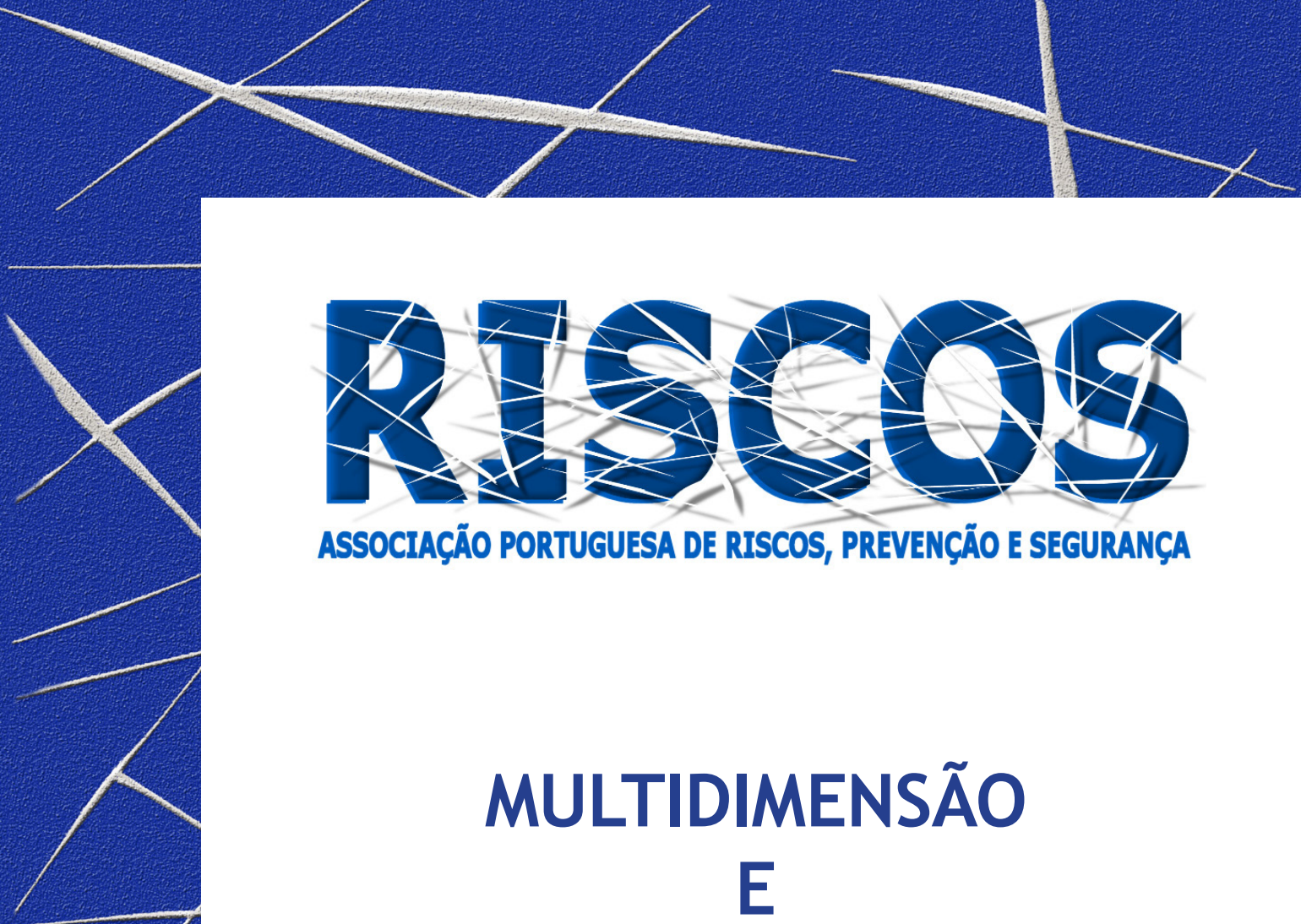

ASSOCIAÇÃO PORTUGUESA DE RISCOS, PREVENCCÃO E SEGURANÇA

MULTIDIMENSÃO

E
TERRITÓRIOS DE RISCO

III Congresso Internacional

I Simpósio Ibero-Americano

VIII Encontro Nacional de Riscos

Guimarães

2014 


\title{
ANÁLISE DE SUSCEPTIBILIDADES E O ORDENAMENTO DO TERRITÓRIO À ESCALA MUNICIPAL - APLICAÇÃO AOS CONCELHOS DE ARRUDA DOS VINHOS E VILA FRANCA DE XIRA
}

\author{
Inês Bruno \\ Instituto Superior de Educação e Ciências \\ inesfbruno@yahoo.com.br \\ Henrique Vicêncio \\ Instituto Superior de Educação e Ciências \\ henrique.vicencio@gmail.com
}

\begin{abstract}
RESUMO
É cada vez mais frequente ouvir o relato da ocorrência de fenómenos perigosos e seus danos socioeconómicos o que se deve, em parte, a um aumento da frequência e intensidade de alguns fenómenos naturais extremos. Conjugado com esta realidade, o aumento da exposição das populações a estes fenómenos revela a importância do ordenamento do território na gestão da interação homem/espaço natural.

Apresenta-se uma metodologia que identifica as melhores opções para a ocupação do território tendo em vista a segurança de pessoas e bens, aplicada aos concelhos de Arruda dos Vinhos e Vila Franca de Xira. Concluiu-se que a superfície sujeita a interdições ou condicionalismos é de $47 \%$ e de $93 \%$ das superfícies dos concelhos (Arruda dos Vinhos e Vila Franca de Xira, respectivamente), e que o número de edifícios localizados em áreas com restrições na ocupação do solo é 1.722 em Arruda dos Vinhos e 34.407 em Vila Franca de Xira.
\end{abstract}

Palavras-chave: Ordenamento do Território; Suscetibilidades; Riscos.

\section{Introdução}

Portugal está sujeito de forma diversa aos perigos naturais e tecnológicos que podem originar catástrofes e não apresenta um ordenamento territorial que tenha em conta a identificação e caracterização dos riscos. Esta situação, associada a outros fatores, tem contribuído para um aumento dos danos socioeconómicos associados à ocorrência de catástrofes.

Os possíveis impactos nas estruturas já construídas em áreas de perigo deverão ser mitigados com o recurso a sistemas de monitorização, alerta e aviso, preparação para a resposta, informação e envolvimento da população em exercícios.

\section{Metodologia}

A metodologia de análise do território compreendeu 4 passos: 1 - Identificação das fontes de perigo; 2 - Definição do número de classes de permissão; 3 - Obtenção da matriz final; 5 Classificação para uma nova escala de permissões e obtenção do mapa final. Este método utiliza um elevado número de dados ponderados em ambiente de Sistemas de Informação Geográfica (Çabuk, 2001; Çabuk et al., 2006; Riad et al., 2011).

A identificação das fontes de perigo consistiu na pesquisa e consulta de Planos Diretores Municipais, Planos Municipais de Emergência e base de dados de ocorrências da Autoridade Nacional de Proteção Civil.

Foram consideradas quatro classes de permissão para as fontes de perigo que traduzem a aptidão do território para a ocupação, tabela I. 
Tabela I - Tabela de permissões

\begin{tabular}{|c|c|}
\hline Classes de permissão & Características \\
\hline Interdito & Não é permitida a construção de estruturas. Perigo de morte ou danos irreversíveis para a saúde. \\
\hline Permissão de $3 .^{\circ}$ grau & $\begin{array}{l}\text { Fortes limitações à construção de estruturas. A sua ocupação requer obrigatoriamente medidas de } \\
\text { mitigação e a aplicação de sistemas de monitorização, alerta e aviso. }\end{array}$ \\
\hline Permissão de $2 .^{\circ}$ grau & $\begin{array}{l}\text { Existem limitações à construção de estruturas, para as quais poderão vir a ser necessárias medidas } \\
\text { de prevenção/mitigação. É necessário parecer/autorização da administração. }\end{array}$ \\
\hline Permissão de $1 .^{\circ} \mathrm{grau}$ & É permitida a construção de estruturas. \\
\hline
\end{tabular}

A atribuição de pontuações às classes de permissão torna-se fundamental no cruzamento de dados e construção final do mapa de permissões. As fontes de perigo apresentam diferentes unidades de medida pelo que se optou por atribuir diferentes pontuações às classes de permissão, tabela II.

Tabela II - Classificação das permissões

\begin{tabular}{cc}
\hline Classes de permissão & Pontuação \\
\hline Interdito & 0 \\
Permissão de $3 .^{\circ}$ grau & 1 \\
Permissão de $2 .^{\circ}$ grau & 2 \\
Permissão de $1 .^{\circ}$ grau & 3 \\
\hline
\end{tabular}

Aplicou-se esta pontuação a cada uma das fontes de perigos identificados, obtendo-se um conjunto de matrizes que, por multiplicação, deram origem a uma matriz reclassificada segundo critérios e valores da tabela III, de modo a obter-se a matriz final.

\section{Tabela III - Classificação das permissões}

\begin{tabular}{lcc}
\hline \multicolumn{1}{c}{ Limites de reclassificação (resultado da multiplicação) } & $\begin{array}{l}\text { Intervalo de valores das células da } \\
\text { matriz resultante da multiplicação }\end{array}$ & $\begin{array}{c}\text { Valor das células da } \\
\text { matriz final }\end{array}$ \\
\hline $\begin{array}{l}\text { A - Pelo menos um multiplicador corresponde à existência de } \\
\text { interdição à construção de estruturas (zero). }\end{array}$ & \{resultado de A\} \\
$\begin{array}{l}\text { B - Todos os multiplicadores correspondem à menor classe de } \\
\text { permissão à construção de estruturas (um). }\end{array}$ & [resultado de B, resultado de C [ \\
$\begin{array}{l}\text { C - Todos os multiplicadores correspondem a uma classe } \\
\text { intermédia de permissão à construção de estruturas (dois). }\end{array}$ & [resultado de C, resultado de D [ \\
$\begin{array}{l}\text { D - Todos os multiplicadores correspondem à maior classe de } \\
\text { permissão à construção de estruturas (três). }\end{array}$ & \{resultado de D\} \\
\hline
\end{tabular}

A matriz final permitiu a construção de um mapa com quatro classes de permissão.

Aplicou-se esta metodologia aos municípios de Arruda dos Vinhos e Vila Franca de Xira, vulneráveis a cheias, inundações, incêndios florestais, e deslizamentos de terras apresentando ainda estabelecimentos Seveso em áreas urbanizadas.

Foram identificadas 6 fontes de perigo em Arruda dos Vinhos e 11 em Vila Franca de Xira, tabela IV.

Tabela IV - Fontes de perigo e riscos associados

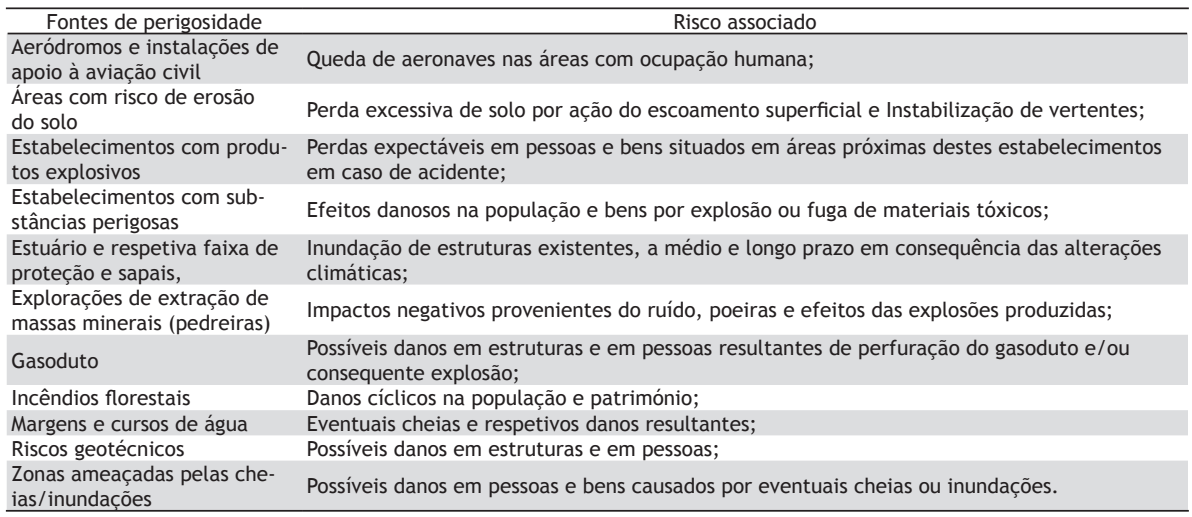


Em função das suscetibilidades existentes, aplicaram-se os critérios da tabela I aos dois concelhos, tendo-se obtido os resultados constantes da tabela V.

Tabela V - Fontes de perigo, áreas de suscetibilidade, classes de permissão e pontos de permissão dos concelhos de Arruda dos Vinhos e Vila Franca de Xira

\begin{tabular}{|c|c|c|c|}
\hline Fontes de perigo & Áreas de suscetibilidade & $\begin{array}{l}\text { Classes de } \\
\text { permissão }\end{array}$ & $\begin{array}{l}\text { Pontos de } \\
\text { permissão }\end{array}$ \\
\hline Aeródromo Alverca & Zona Geral de Proteção & $2 .^{\circ} \mathrm{grau}$ & 2 \\
\hline Áreas Risco de Erosão & Áreas Risco de Erosão & Interdito & 0 \\
\hline \multirow{3}{*}{ Seveso - Arruda dos Vinhos } & 0-122 metros & Interdito & 0 \\
\hline & 122-154 metros & Interdito & 0 \\
\hline & $154-410$ metros & $3 .^{\circ}$ grau & 1 \\
\hline Seveso - Vila Franca de Xira & Efeitos Irreversíveis & Interdito & 0 \\
\hline Estuário, Faixa de Proteção e Sapais & Estuário, Faixa de Proteção e Sapais & Interdito & 0 \\
\hline Pedreiras & Pedreiras & Interdito & 0 \\
\hline Gasodutos & $0-10$ metros & Interdito & 0 \\
\hline Incêndios Florestais & Perigosidade Alta e Muito Alta & Interdito & 0 \\
\hline Margens e Cursos de Água & Margens e Cursos de Água em Espaço Urbano & $2 .^{\circ}$ grau & 2 \\
\hline $\begin{array}{l}\text { Zonas Ameaçadas Cheias - Arruda dos } \\
\text { Vinhos }\end{array}$ & Restantes Zonas Ameaçadas Cheias & Interdito & 0 \\
\hline \multirow{2}{*}{$\begin{array}{c}\text { Zonas Ameaçadas Cheias - Vila Franca } \\
\text { de Xira } \\
\end{array}$} & Zonas Ameaçadas Cheias em Solo Urbano Edificado & $2 .^{\circ}$ grau & 2 \\
\hline & Restantes Zonas Ameaçadas Cheias & Interdito & 0 \\
\hline
\end{tabular}

Após a multiplicação das matrizes correspondentes a cada tipologia de fontes de perigo, reclassificaram-se os valores de cada elemento da matriz final. A tabela VI mostra os intervalos utilizados na reclassificação das escalas de permissões.

Tabela VI - Valores utilizados na reclassificação para os dois concelhos

\begin{tabular}{|c|c|c|c|}
\hline \multicolumn{2}{|c|}{ Intervalos de permissão } & Classe final de permis- & \\
\cline { 4 - 5 } saro & Vila Franca de Xira & 0 & \\
\hline 0 & 0 & 1 & Interdito \\
\hline$[1,64[$ & {$[1,2.048[$} & 2 & $3 .^{\circ}$ grau \\
\hline$[64,279[$ & {$[2.048,177.147[$} & 3 & $2 .^{\circ}$ grau \\
\hline 279 & 177.147 & $1 .{ }^{\circ}$ grau (sem restrições) \\
\hline
\end{tabular}

Após a reclassificação dos resultados obtidos calcularam-se as áreas interditas ou condicionadas à construção e somaram-se, para cada concelho.

\section{Resultados}

Verificou-se que o concelho de Vila Franca de Xira apresenta 93\% do seu espaço territorial com restrições, sendo esse valor de 47\% para Arruda dos Vinhos, figura 1.

Sobrepondo-se áreas com restrições às áreas urbanizadas verificou-se a existência de inúmeros edifícios localizados em áreas com restrições à construção. Arruda dos Vinhos apresenta 1.722 edifícios localizados em áreas com restrições (17\% dos edifícios existentes) e Vila Franca de Xira apresenta 34.407 edifícios (75\% dos edifícios existentes no concelho). 

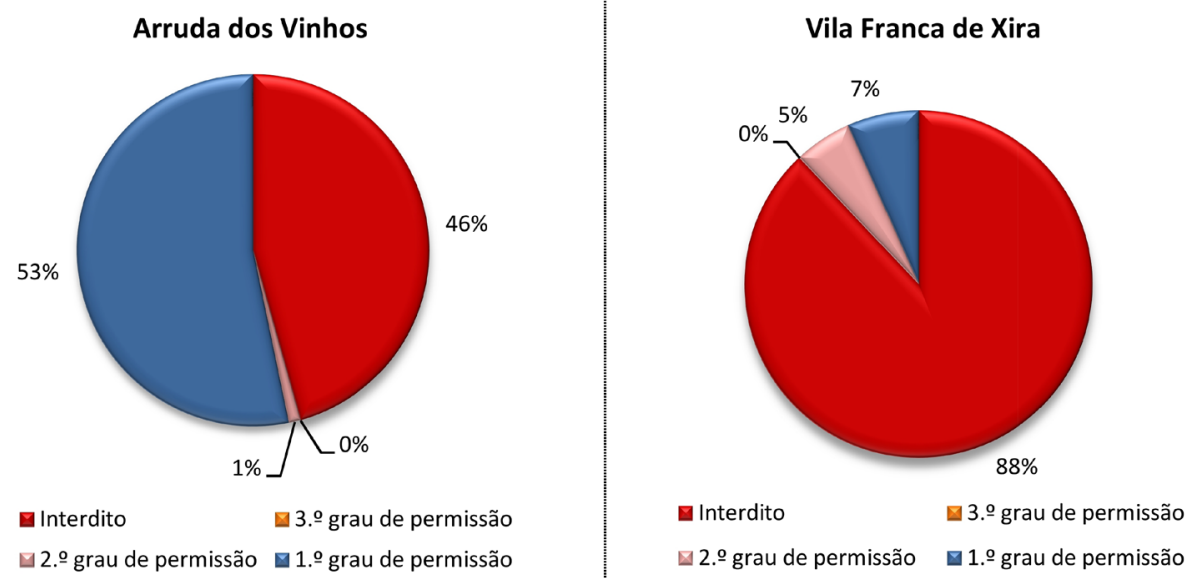

Figura 1 - Distribuição da área do concelho por classes de permissão

\section{Conclusões}

Esta metodologia permitiu identificar um elevado número de estruturas em áreas com restrições à construção, o que na eventualidade de ocorrência de perigos naturais ou tecnológicos poderá contribuir para danos sociais e estruturais avultados. Salienta-se que a existência de restrições no plano formal, sob a forma de leis, não tem impedido a edificação nessas áreas, pelo que se deve questionar a eficácia e utilidade que a legislação preventiva tem tido nas últimas décadas em Portugal. A metodologia desenvolvida e os resultados obtidos podem ser utilizados pela administração central e local no planeamento da ocupação do território a várias escalas, bem como pelas companhias de seguros na identificação de áreas de maior exposição e de maiores perdas potenciais. É importante realçar que existem áreas significativas nos dois concelhos que podem ser ocupadas na construção de edifícios sem pôr em perigo a população, permitindo assim uma poupança nas fases de preparação, resposta e recuperação face a uma catástrofe.

\section{Bibliografia}

Çabuk, A. (2001) - A Proposal for a Method to Establish Natural-Hazard-Based Land-Use Planning: the Adapazari Case Study. Turkish Journal of Earth Sciences, 10, 143-152.

Çabuk, S. N., Dögeroglu, T., Çabuk, A. (2006). Using GIS Capabilities for Strategic Environmental Assessment Studies: Eskisehir Mass Housing Project. Comunicação apresentada no 4th GIS Days in Türkiye. Istanbul, Turquia.

Riad, P. H., Billib M. H., Hassan, A. A. \& Omar, M. A. (2011). Overlay Weighted Model and Fuzzy Logic to Determine the Best Locations for Artificial Recharge of Groundwater in a Semi-Arid Area in Egypt. Nile Basin Water Science \& Engineering Journal, 4, 24-35. 